Research Article

\title{
Computer Modelling of Linear Friction Welding Based on the Joint Microstructure
}

\author{
S.K. Kiselyeva ${ }^{1}$, A.M. Yamileva ${ }^{1, *}$, M.V. Karavaeva ${ }^{1}$, I.Sh. Nasibullayev ${ }^{1}$, V.M. Bychkov ${ }^{1}$, \\ A.Yu. Medvedev ${ }^{1}$, A.V. Supov ${ }^{2}$, F.F. Musin ${ }^{1}$, I.V. Alexandrov' ${ }^{1}$, V.V. Latysh ${ }^{1}$ \\ ${ }^{1}$ Ufa State Aviation Technical University, 450000, Russia, Ufa, K.Marx Str., 12 \\ ${ }^{2}$ JSC Ufa Engine-Building Industrial Association, 450039, Russia, Ufa, Ferin Str., 2
}

Received 15 July 2012; Accepted 25 July 2012

\begin{abstract}
The linear friction welding process of $\alpha+\beta$ titanium alloys VT6 and VT8M-1 has been studied and in particular the investigation of microstructure in the weld zone. The results of this investigation were used for development of a numerical model of LFW equilibrium stage using the ANSYS Mechanical software. The set of parameters used in this model allowed to reach a quantitative agreement with experiments
\end{abstract}

Keywords: linear friction welding, computational experiment, microstructure

\section{Introduction}

Friction welding is an efficient manufacturing process which allows the solid state joining of different metals using frictional heat generated from their relative motion. In this family of processes, the first to be developed commercially was to join axially symmetric bodies and was named rotation friction welding. More recently friction welding started gaining more attention with the development of another variant, linear friction welding (LFW). Considerable interest in LFW has been shown as it can join objects of arbitrary shape, which is of particular interest to aircraft engine engineering.

The formation of a joint with LFW can be divided into four stages [1-4]. At initial stage the surfaces to be joined come into contact under normal load. At the second stage (transition) heat generation in the contact area takes place due to friction between the oscillating parts, while the material layer adjacent to the weld line yields. The third stage (equilibrium) is characterized by the fact that plastic material is squeezed out of the contact area, forming the socalled "flash", under the influence of normal loading. At the fourth stage (forging) movement is stopped and interatomic connections between opposing specimens form to weld.

The normal load applied to workpieces results in their axial shortening, which increases with welding time. This deformation occurs in a narrow zone near the weld line, where there is considerable heating of the metal as a result of friction. Heating of welded workpieces can lead to changes in microstructure, which in turn may lead to a catastrophic degradation of the mechanical properties of materials in the welding area.

\footnotetext{
* E-mail address: a.yamileva@gmail.com

ISSN: 1791-2377 @ 2012 Kavala Institute of Technology. All rights reserved.
}

One of the most significant problems to be considered in LFW is the optimization of process parameters to obtain a microstructure which will posses all the required mechanical properties of the joint materials in the welding zone.

It is known that development of computer models based on a limited number of experiments allows the reduction of the number of expensive experiments considerably, and replaces them by simulation with engineering software packages on a supercomputer.

In particular, during linear friction welding a computer model should allow the estimation of the heat affected zone, which is especially important in welding dissimilar material joints.

The main difficulty with the development of a computer model of the LFW process is the simulation of large plastic deformations at the third stage and, in particular, the formation of flash. In literature [5] there has been developed a F.E. model of thermo-elastic deformations of two samples during LFW with the removal of material layers to the flash in the contact area according to a specified criterion. The removal of a material layer is performed with transition of the temperature field to an assigned thickness, without actually removing the finite elements and altering the stress field. This technique allows the employment of a fine finite element mesh only in the contact zone reduced therefore the computation time considerably.

Unlike this model [5], where the minimum thickness of the removed layer cannot be less than the element size, in the proposed model in this work there is the possibility of the removal of a layer of arbitrary thickness without reference to the mesh in use.

The aim of this work is the development of an adequate computer model of the second and third stage of LFW process, which will be in agreement with existing experimental data, and more specifically, the axial 
shortening dynamics and the width of the plastic deformation zone.

\section{Research Procedure}

Samples from $\alpha+\beta$ Ti alloys VT6 and VT8M-1 with specified chemical composition (see Tab.1) have been linear friction welded using the machine PDS (Progress Development System) of the JSC "Ufa Engine Industrial Association" firm. The temperature of the complete polymorphic transformation has been determined by quenching and was found to be $975{ }^{\circ} \mathrm{C}$ for the VT6 alloy and $1020{ }^{\circ} \mathrm{C}$ for the VT8M-1 alloy.

Table 1. Chemical composition of the alloys

\begin{tabular}{l|c|c|c|c|c}
\hline \multicolumn{1}{c|}{ Alloy } & Al & V & Zr & Mo & Sn \\
\hline VT6 & 6,1 & 5,2 & - & - & - \\
\hline VT8M-1 & 5,0 & - & 1,5 & 4,3 & 1,3 \\
\hline
\end{tabular}

Samples to be welded had a cross section of $13 \times 26 \mathrm{~mm}^{2}$. The PDS machine has a system of hydraulic controls which provides the oscillating movement at the prescribed frequency and amplitude of oscillation and allows for forging after movement is arrested. The process time is controlled by assigning an axial shortening value after which has been reached oscillatory movement is arrested. Thus, the most important parameters which determine welding behavior are the frequency $f$ and amplitude $a$ of oscillation, normal force $F_{1}$, forging force $F_{2}$ and the axial shortening value $h$.

The following parameters of the process were chosen: $a$ $=2 \mathrm{~mm}, f=50 \mathrm{~Hz}$, welding and forging force $F_{1}=F_{2}=35$ $\mathrm{kN}$. It has been demonstrated earlier [6] by the authors that the quality of the joint depends on the value of axial shortening. Defect-free welded joints are achieved when axial shortening is bigger than $1.4 \mathrm{~mm}$. Therefore the value of axial shortening in this research was chosen to be $1.9 \mathrm{~mm}$.

The metallographic sections for microstructural research have been prepared in the central weld zone of the rectangular welded sample. To reveal the microstructure the prepared sections have been ground and etched with nitric and hydrofluoric acid solution in water in proportion 10:15:75 to studied under an optical microscope "OLYMPUS GX-51".

\section{The investigation of alloy microstructure in the weld zone}

The microstructure of contact of the welded materials can be divided into 4 zones: 1 - recrystallization; 2 - large plastic deformation; 3 - transition; 4 - base metal (Fig. 1). These zones have different etchable, size and shape of grains. In particular:

Zone 1 is the most difficult to etch, where the coarse almost equiaxial grains of $\beta$-transformed grains are present. The equiaxial shape of $\beta$-grains indicates that they have been formed after the end of plastic deformation.

Zone 2 is characterized by grains of metal which are elongated in the direction of movement. Such a structure is the result of large plastic deformation in a two-phase $(\alpha+\beta)$ area.

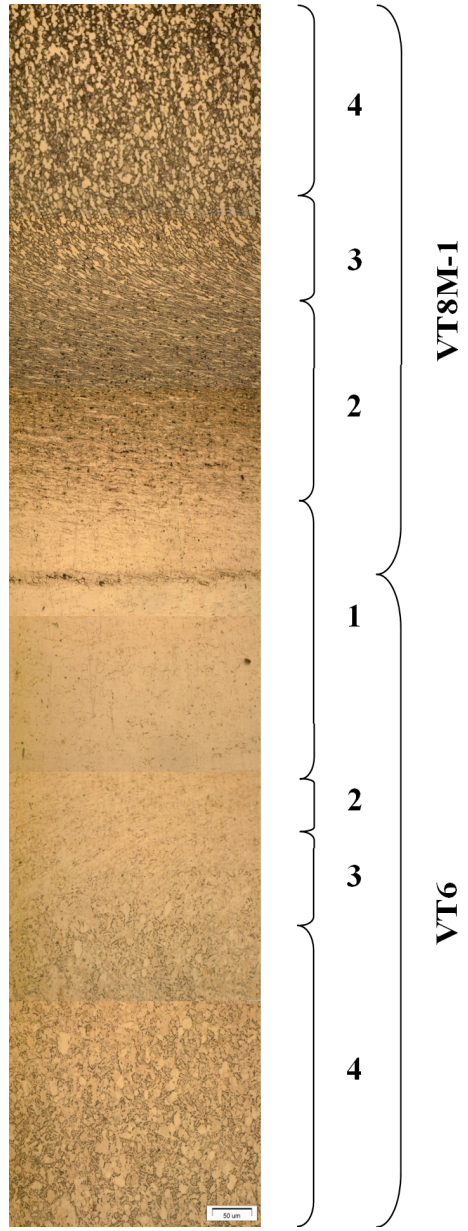

Fig. 1. Microstructure of the welded joint for axial shortening $1.9 \mathrm{~mm}$

Zone 3 is the transition from base metal which does not suffer from deformation to the zone of large plastic deformation (zone 2). There are appears a partial turn of metal grains in the direction of movement where there are large deformations in the other zones..

Zone 4 is the base metal, which doesn't suffer from any significant thermal or mechanical effects from the process and posses the initial microstructure of the specimens.

All these zones can be observed in both welded samples. However, the width of the zones for VT6 and VT8M-1 alloys differ, as it can be seen in Fig. 1 .

The width of the recrystallized zone 1 is large in VT6, while the zone of large plastic deformations 2 is bigger in VT8M-1. This can be explained by the fact that a narrow area next to the joint is subjected to high temperatures during friction welding. The temperature decreases rapidly further away from the welding line [1, 2]. The observed microstructural changes are due to the temperature at the contact zone which was higher than the phase change temperature of both alloys. However, the phase change temperature of VT6 is lower than that of VT8M-1. Therefore, the heated area with phase change in VT6 is wider. In the deformed $\beta$-phase area after removal of loading, recrystallization with the development of equiaxial grains appears very quickly (zone 1). It is therefore, zone 1 the area of large plastic deformation.

\section{Computer modeling}

A 2D computer model of the second and third stages of LFW has been developed using the engineering software 
package ANSYS Mechanical. The geometry of the model has rectangular pieces with dimensions $26 \mathrm{~mm} \times 5 \mathrm{~mm}$ (Fig. $2)$. In the simulation is used area which includes heataffected zone, and the high stress zone, which composes about $5 \mathrm{~mm}$ in height from the contact area. Note, that real samples dimension is $26 \mathrm{~mm} \times 35 \mathrm{~mm}$. The boundary conditions are those described earlier, same as the ones used in the PDS machine. The lower sample is constrained vertically and moves relative to the upper one along the axis $X$ with a sinusoidal motion

$$
x=a \cdot \sin (\omega \cdot t)
$$

whereas the amplitude of oscillation $a$ is increasing linearly from 0 to $2 \mathrm{~mm}$ in $0.1 \mathrm{sec}$ while moving at a frequency $f=$ $50 \mathrm{~Hz}$. Pressure is assigned to the whole upper face of the top sample, which also increases from $15 \mathrm{kN}$ to $35 \mathrm{kN}$ at a rate of $100 \mathrm{kN} / \mathrm{sec}$ at the beginning of the process in a similar fashion as in the experimental machine.

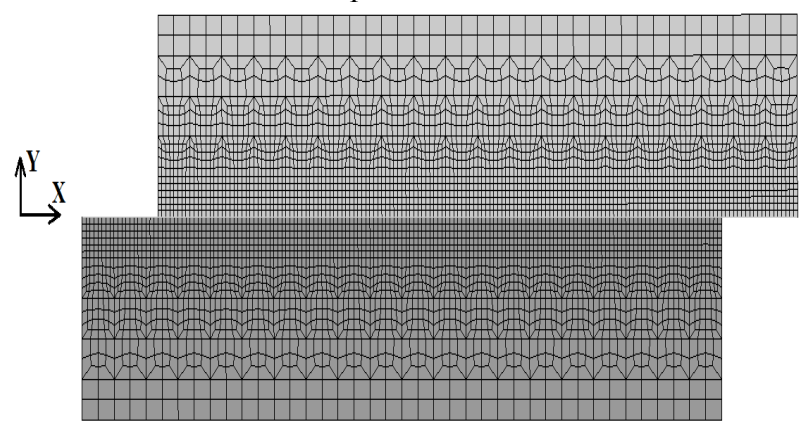

Fig. 2. Finite element mesh

Initial temperature of the samples is uniformly set at $293 \mathrm{~K}$. The process is considered to be adiabatic due to short process duration. The material properties of VT8M-1 for the upper sample and VT6 for the lower one are used. An isotropic elastic model is considered here in this model. The friction coefficient $\lambda(T)$ increases linearly up to a temperature of $893 \mathrm{~K}$ by:

$$
\lambda(T)=0.3+5 \cdot 10^{-4}(T-293)
$$

and when the temperature exceeds $893 \mathrm{~K}$ remains constant to 0.6 .

When modeling the $3^{\text {rd }}$ stage of the process it is necessary to take into account large plastic deformations that form the flash. In this work the model developed is a thermo-elastic model with the removal of material layer in the contact area, using the following parameters:

1) the proportion of frictional energy transforming into heat $\left(k_{1}\right)$,

2) the proportion of frictional energy used for microstructural change $\left(1-k_{1}\right)$,

$3)$ the criterion used to remove layers is the amount of plastic material which moves into the flash $\left(k_{2}\right)$,

$4)$ the proportion of the plastic zone remaining in the final plastic zone (1- $\left.k_{2}\right)$, which is sum of zones 1 and 2 (Fig. 1).

Using the F.E. model to calculate the temperature and stress fields the thickness of the material layer which yields is estimated. Using the results of this calculation that part of material is removed, simulating the squeezing out of material into the flash, and the procedure is repeated .

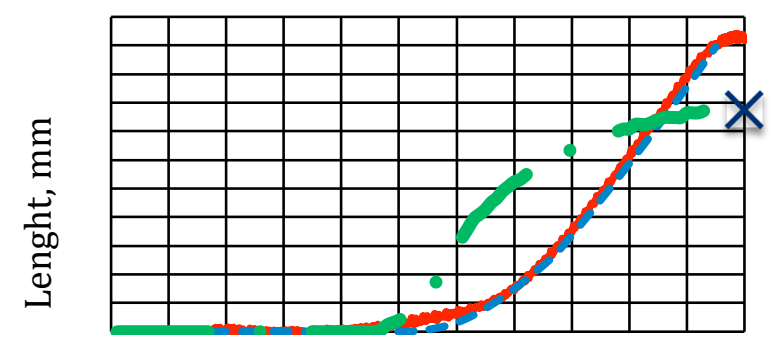

Time, s

Fig. 3. Axial shortening change with time (experiment (-), modeling ($-)$, width of the plastic zone experiment $(\times)$ and in the modeling $(-\bullet-)$

Figure 3 shows axial shortening history as calculated by the F.E. analysis and experimental data are presented for comparison. The difference in values between experiment and modeling is less than $6 \%$ for the linear part of the diagram. Analysis of the microstructure in the weldline of VT6 and VT8M-1 after linear friction welding has shown that the width (for both samples) of the plastic deformation zone is $1.55 \mathrm{~mm}$ for an axial shortening of $1.9 \mathrm{~mm}$. The total width of the plastic deformation zone estimated using the F.E. mode for an axial shortening of $1.9 \mathrm{~mm}$ was $1.57 \mathrm{~mm}$ (Fig. 3), an overestimation of $2 \%$ from actual data. The developed numerical model has shown a good quantitative agreement with experiments, validating it for further use.

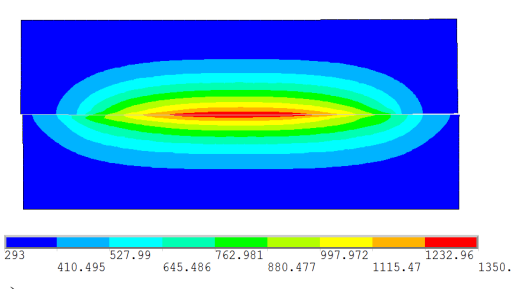

a)

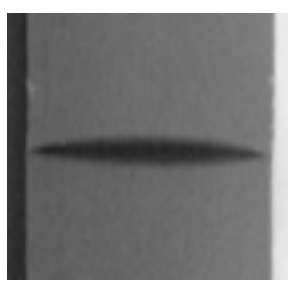

b)

Fig. 4. Temperature field $(\mathrm{K})$ at $\mathrm{t}=1.05 \mathrm{~s}$ after beginning of motion (a) and macrostructure of the samples after joining(b)

Figure $4 \mathrm{a}$ shows the variation of temperature at time 1.05 sec into the process, as calculated by the FE model. The maximum temperature is observed to be in the centre point of the contact area reaching about $1350 \mathrm{~K}$. The macrostructure of the samples after welding is presented for comparison (Fig. 4b) of the shape of high temperature zone. There is qualitative agreement in the shape of the heat affected zone in both numerical models and welded specimens as they are both concave.

\section{Conclusions}

If has been shown that considerable microstructural changes occur in the welding zone under the thermo-mechanical action of LFW. The following zones have been identified to form during LFW: a recrystallized zone, a zone of large plastic deformation, a transition zone and base metal.

A numerical model of the second and third stage of linear friction welding have been developed using ANSYS Mechanical based on experimental data (axial shortening value and the width of the plastic zone). The set of parameters used in this model produced quantitative agreement with experiments.

It should be noted that this investigation is an important 
step in the way of developing an accurate $2 \mathrm{D}$ model of the whole process. The next step in the development of this model is the calculation of the residual stresses formed at the last stage of the process.

Acknowledgements

This work was produced for the project "The Technology and Manufacturing Production of the Components and Blades of Gas-Turbine Engines with Lightweight High-
Strength Constructions for Aircraft Engines of New Generation", supported by the Federal Target Program according to the RF Government Regulation №218 from April, the $9^{\text {th }}$, 2010, "About the measures of State support for development of co-operation of Russian higher education establishments and organizations, realizing the complex projects in developing high-quality production".

\section{References}

1. A. Vairis, M. Frost. On the extrusion stage of linear friction welding of Ti6A14V. Material Science and Engineering, , A 271, 477 (1999).

2. W.-Y. Li, T.J. Ma, S.Q. Yang. Effect of friction time on flash shape and axial shortening of linear friction welded 45 steel. Mat. Letters, 62, 293 (2008).

3. W.-Y. Li, T.J. Ma, J. Li. Numerical simulation of linear friction welding of titanium alloy: Effect of processing parameters. Materials and Design, 31, 1497 (2010).
4. T. Mohandas, D. Banerjee, V.V. Kutumba Rao. Microstructure and mechanical properties of friction welds of an $\alpha+\beta$ titanium alloy. Materials Science and Engineering, A 289, 1, 70 (2010).

5. J. Sorina-Müller, M. Rettenmayr, D. Schneefeld, O. Roder, W. Fried. FEM simulation of the linear friction welding of titanium alloys, J. Computational Materials Science, 48 , 749 (2010).

6. M.V. Karavaeva, S.K. Kiseleva, V.M. Bychkov, A.Yu. Medvedev, A.V. Supov, F.F. Musin, I.V. Alexandrov, V.V. Latysh. Effect of the shortening on formation welding under linear friction welding. Letters on Materials, 2 , 40 (in Russian) (2012). 